Cad.Est.Ling., Campinas, 47(1) e (2):167-174, 2005

\title{
CONSIDERAÇÕES SOBRE A ESCUTA NA CLÍNICA DE LINGUAGEM
}

\author{
LOURDES ANDRADE \\ (Derdic, Pontifícia Universidade CATólicA-SP)
}

\begin{abstract}
In the field of speech pathology and therapy, perception-based models are central, both as explanatory tools for pathological speech conditions and as the basis to the development and implementation of therapeutic procedures. Such approach is submitted to critical discussion and an alternative perspective is put forward. The first step towards the alternative approach proposed involves a discussion on the nature of linguistic materiality and the drawing of a distinction between hearing (an organic ability) and listening (involving the unique relationship between speaker and language). In order to explore this subject I discuss the ways Linguistics and Psychoanalysis can provide the field of speech therapy with a theoretical framework which allows for a new perspective on the relationship speaker-language. This discussion is conducted in accordance with the reflections on child language developed by Cláudia Lemos.
\end{abstract}

Nesta publicação em homenagem à Prof ${ }^{a}$. Cláudia Lemos, procurarei registrar o reconhecimento dos efeitos instigantes que seu trabalho tem provocado, ao longo do tempo, em outras áreas, como a das patologias e clínica de linguagem. Faço isso na condição de fonoaudióloga formada em 1982 - ano em que aparece seu trabalho Aquisição de Linguagem e seu dilema (pecado) original. No tempo transcorrido desde então, muitas foram as mudanças na proposta Interacionista e o impacto produzido numa parte pequena, porém significativa, do campo das patologias e da clínica fonoaudiológica. Trata-se de uma trajetória que se distancia de uma prática fonoaudiológica de contornos inespecíficos e aponta para a possibilidade de constituição de uma clínica de linguagem.

Essa trajetória traz a marca de uma relação particular com o trabalho de Cláudia Lemos - particular porque pautada por um duplo compromisso: o de uma aproximação não utilitária/aplicativa ao espaço teórico-metodológico por ele instituído, bem como o compromisso com as questões próprias ao campo das patologias de linguagem. Nesse sentido, a reflexão de Cláudia Lemos, no campo da Aquisição da Linguagem, tem se constituído "como um lugar onde o que se sabe serve, acima de tudo, para interrogar e se transforma em um saber interrogar", como afirma a própria autora ao discutir o estabelecimento de relações entre disciplinas (1998). É essa a natureza do movimento realizado por pesquisadores do Projeto Aquisição da Linguagem e Patologias da Linguagem, do qual faço parte e que vem sendo desenvolvido no LAEL/PUCSP, sob coordenação de Maria Francisca Lier-De Vitto. 
É do interior desse movimento que pretendo fazer algumas pontuações sobre a distinção entre ouvir e escutar enquanto questão para a clínica de linguagem. Estarei, portanto, voltada para o estatuto da percepção quando se trata de linguagem.

Essa reflexão teve início em trabalho anterior (Andrade, 2000), em que aponto para a centralidade da percepção no campo da Fonoaudiologia, tanto no que diz respeito a modelos explicativos de condições sintomáticas, quanto no que diz respeito ao desenvolvimento e implementação de procedimentos terapêuticos. Nesse campo, o que o terapeuta entende por percepção resume-se ao ouvir, quer dizer, à faculdade de apreensão - via órgãos dos sentidos - de objetos externos. Entendimento esse que determina procedimentos clínicos voltados para a estimulação dessa capacidade que se supõe prejudicada e que, por sua vez, é assumida como condição para a aquisição de conhecimentos - entre eles, a linguagem.

Pretendo, neste trabalho, avançar algumas considerações sobre a natureza da materialidade lingüística, o que exige o estabelecimento de uma distinção entre ouvir e escutar: ouvir como capacidade/condição orgânica e escutar como efeito da relação de um sujeito à fala.

Na Fonoaudiologia, em que predomina o ouvir, a linguagem é tomada como um objeto a conhecer - que pode ser naturalmente apreendido por um indivíduo devidamente dotado de capacidades perceptuais e cognitivas. Nesse contexto, as proposições problemáticas relativas à questão do acesso à linguagem - e que dizem respeito à relação criança-outro-linguagem - são desconsideradas. Isso porque a linguagem é assumida como objeto cujas propriedades podem ser diretamente apreensíveis na superfície da fala. Disso decorrem concepções de sujeito e de outro bastante particulares: outro que, ao falar, oferece a linguagem como objeto de que o sujeito, através da percepção, toma posse. À transparência da linguagem correspondem, portanto, o outro como modelo e o sujeito como suficiente é ele que percebe, discrimina, apreende/aprende. Sob essa ótica, a fala para o fonoaudiólogo reduz-se a uma sucessão de elementos discretos e discerníveis que estimulam um aparato perceptual já preparado para exercer funções de captação e processamento.

A pressuposição de uma ligação intrínseca - ou natural - entre audição e linguagem, no entanto, encontra seu limite quando a questão é responder pelo sentido/significado: se a responsabilidade pela apreensão da forma lingüística pode ser atribuída diretamente a mecanismos perceptuais, o mesmo não se pode dizer em relação aos significados por ela veiculados. Esse impedimento fica claro se considerarmos que o que sustenta o argumento de apreensibilidade, via mecanismos perceptuais, é o fato de que a forma lingüística repousa numa materialidade que pode, supostamente, ser abordada a partir das características físicas do som da fala. O sentido/significado, por sua vez, impõe resistência a essa suposição na medida em que não é apreensível diretamente.

Esse impasse é contornado por uma dupla tendência: (a) entender o sentido como referência, ou seja, que o signo designa o aqui e agora de uma situação, estabelecendo uma relação direta palavra-mundo; e (b) supor uma relação palavra-pensamento em que a linguagem está a serviço de representações internas. Em ambas as tendências, a linguagem não participa na estruturação do sentido, configurando-se como ferramenta de que o falante faz uso para dizer o mundo ou expressar desejos, intenções, opiniões etc. Aqui, a esfera cognitiva é chamada a fazer complemento à esfera perceptual na abordagem da fala. 
Cadernos de Estudos Lingüísticos 47(1) e (2) - Jan./Dez. 2005

Na Fonoaudiologia assim configurada, portanto, se há um problema de linguagem e se o processamento do lingüístico depende das esferas perceptual e cognitiva, os procedimentos de avaliação voltam-se para ambas as esferas com objetivo de detectar a falha subjacente ao problema. No entanto, esteja ela localizada na esfera perceptual, esteja localizada na esfera cognitiva, os procedimentos clínicos subseqüientes tendem fortemente a apostar no aspecto perceptual, já que dele depende a acessibilidade aos objetos a adquirir. Deve-se chamar a atenção para o fato de que, localizado um problema de natureza cognitiva subjacente ao problema de linguagem busca-se, novamente através de investimento no perceptual, facilitar o caminho da criança em direção ao que, em si, não se dá a ver. Refirome aqui às práticas que visam dar maior visibilidade a determinados conceitos semânticos e formais. Trata-se de atividades voltadas para a apreensão de categorias semânticas (em que o traço comum entre diversos objetos é enfatizado), apreensão de conceitos de temporalidade e causalidade, ou até mesmo de noções subjacentes a estruturas e categorias lingüísticas (sujeito, verbo, advérbio, conjunção etc.). A idéia parece ser a de 'levar a criança a perceber' o laço entre a forma fônica e o sentido semântico ou formal ali supostamente representado.

Nesse sentido, observam-se, em terapia, tanto estratégias de aproximação da criança a determinados conceitos, através do próprio discurso do terapeuta que, no diálogo com a criança, tem sua fala pautada pelo objetivo de dar saliência perceptual a determinados conceitos (e formas) que faltariam à criança ${ }^{1}$, quanto à utilização de jogos ou materiais específicos nos quais conceitos estariam representados através de figuras: cartelas com figuras a serem seqüenciadas numa narrativa; cartelas com figuras a serem pareadas com o objetivo de exercitar sinônimos, antônimos, enfim, classes e sub-classes semânticas².

A partir da adoção dessa perspectiva, a questão teórico-metodológica central gira em torno do estabelecimento de unidades perceptuais para a fala. Esse movimento em direção à circunscrição de unidades produz efeitos inevitáveis na condução da prática fonoaudiológica: ela é governada por um raciocínio adaptativo, ou seja, o da correção pontual, via treinamento metódico ou mesmo informal, de segmentos desviantes. Está aí uma certa concepção de relação do ser vivo com o meio: a de que ele recebe uma estimulação e produz uma resposta. A explicação para o surgimento de respostas desviantes em relação ao estímulo, portanto, é invariavelmente remetida ao indivíduo, a desvios em seu aparato perceptual.

Essa configuração da prática fonoaudiológica, bem como a noção de indivíduo que aí comparece, tem laços claros com o pensamento estabelecido pela clínica médica, seu modelo e ponto de partida. Se "o médico, com relação ao corpo, tem a atitude do homem que está desmontando uma máquina”, como afirma Lacan (1954/87, p. 97), na perspectiva acima delineada, não é diferente a atitude do fonoaudiólogo frente ao falante.

${ }^{1}$ Exemplos bastante ilustrativos dessa conduta podem ser encontrados em Araújo (2002), que discute a questão da interpretação na clínica fonoaudiológica.

${ }^{2}$ Ainda mais surpreendente nessa abordagem é um material com o qual me deparei recentemente, desenvolvido especificamente para utilização na clínica fonoaudiológica: um conjunto de cartelas com "fotos que representam as diversas categorias lingüísticas" como "adjetivos', "verbos" e assim por diante. 
A partir do que foi apontado em relação à abordagem da fala - como unidades sonoras - e do falante - como aparato perceptual, podemos dizer que, para essa Fonoaudiologia, da fala importa o segmento sonoro e, do falante, aspectos que o reduzem a uma "máquina" de captação e processamento da estimulação externa. Nesse sentido, o que resta da fala é a superfície empírica de sua sonoridade. Quanto ao falante, resta seu organismo - sua orelha/ cérebro - desmembrado em partes/funções específicas. Tais reduções acabam por operar a exclusão do lingüístico e do falante numa clínica que deveria ser de linguagem - fato que não chega a ser reconhecido porque, da atividade clínica assim configurada, é também banida qualquer possibilidade de que a fala do paciente venha a abalar os pressupostos a partir dos quais é abordada. Isso não significa, no entanto, que o que é da ordem da linguagem não insista e ofereça resistência. Seu reconhecimento, no entanto, reduz-se a assinalamentos isolados que não chegam a promover deslocamentos significativos na clínica fonoaudiológica.

A direção tomada, neste trabalho e no Projeto Aquisição de Linguagem e Patologias de Linguagem, para uma ruptura nesse estado de coisas e a instituição de uma clínica que se possa denominar propriamente como de linguagem, como assinalei acima, passa pela filiação à teorização que articula língua, fala e sujeito, desenvolvida por Cláudia Lemos a partir de sua aproximação à lingüística saussureana e à Psicanálise. Filiação, insisto, pautada pelo reconhecimento de diferenças entre campos e, portanto, restringida pelas particularidades impostas pela presença da fala sintomática e pela demanda de ação clínica dela decorrente.

Da reflexão de Cláudia Lemos, alguns pontos são cruciais para a questão que estamos discutindo. $O$ primeiro deles diz respeito à sua oposição tanto às visões empiristas inspiradas na Psicologia, quanto ao inatismo de Chomsky. A partir dessa dupla oposição, a criança, nessa proposta, não pode ser aproximada nem a sujeito epistêmico, nem a indivíduo da espécie. De sua filiação à Psicanálise, especialmente à lacaniana, ela propõe que a criança seja entendida como corpo pulsional, "que demanda interpretação, isto é, corpo que, articulado na e pela linguagem, se acha no regime da demanda e do desejo" (2002, p. 64).

Essa direção é tomada a partir de sua aproximação à lingüística saussureana e o conseqüente reconhecimento da ordem própria da língua, que obriga, nas palavras da autora, "à procura de uma definição clara do sujeito que seria compativel com a concepção de língua na teorização da Lingüística" (De Lemos, 2002).

De fato, no projeto saussureano, a língua não é objeto de conhecimento - propriedades lingüísticas não são observáveis, o que impede sua apreensão por generalização indutiva, ou seja, sua aprendizagem.

Ao contrário da direção tomada pela Fonoaudiologia, Saussure afirma que "a língua apresenta este caráter estranho e surpreendente de não oferecer unidades perceptíveis à primeira vista", ou seja, "a língua não se apresenta como um conjunto de signos delimitados de antemão, dos quais bastasse estudar as significações e a disposição" (Saussure/CLG, p. 123). A ausência de unidades concretas imediatamente reconhecíveis, no entanto, não significa, para ele, que sua delimitação não seja essencial, mesmo porque a língua é vista como um sistema baseado na relação entre unidades concretas. "Unidades", no entanto, são efeitos de relações e sua determinação é reconhecida como um problema complexo. 
Cadernos de Estudos Lingüísticos 47(1) e (2) - Jan./Dez. 2005

Diz ele: "É dificílimo desenredar, numa cadeia fônica, o jogo das unidades nela contidas e dizer sobre quais elementos concretos a língua opera" (Saussure, ibid.). Dificuldade que se coloca para o investigador, mas que, segundo Saussure, os falantes não conhecem: "tudo o que for significativo num grau qualquer aparece-lhes como um elemento concreto", afirma. (id., ibid.).

O significante lingüístico, em sua essência, acrescenta ele, "é [...] constituído não por sua substância material, mas unicamente pelas diferenças que separam sua imagem acústica de todas as outras" (Saussure, ibid., p. 137/8). É nesse sentido que a imagem acústica não se confunde com o elemento tangível que lhe serve de suporte: a sonoridade é "matéria que a língua põe em jogo" (id., ibid., p. 137).

Fica claro, a partir daí, porque "jamais um fragmento de língua poderá basear-se [...] noutra coisa que não seja sua não-coincidência com o resto" (id., ibid.) e também a afirmação de Saussure de que, sendo "a língua uma forma e não uma substância [...] todas as maneiras incorretas de designar as coisas da língua provêm da suposição de que haveria uma substância no fenômeno lingüístico (ibid., p. 141)."

Entendem-se, assim, as restrições que essa visão coloca à sua articulação com uma noção de sujeito: não se pode supor à criança, a partir daí, uma condição perceptual ou cognitiva que governe seu acesso à linguagem.

No que diz respeito à abordagem da fala, portanto, a reflexão saussureana promove deslocamentos significativos à medida que uma noção de língua é implicada. A implicação da língua no tratamento dado à fala promove um abalo naquilo que é central na Fonoaudiologia: unidades são efeitos de relações e, portanto, só podem ser apreendidas no jogo de relações que as engendra. Isso coloca uma questão contundente em relação à percepção: as "unidades-efeitos-de-relações" não se deixam apreender enquanto substância sonora, o que, por sua vez, dissolve a concepção de um aparato perceptual apto para recolher unidades discretas supostas ao objeto. Não há percepção pronta: nesse enquadre, há deslocamento tanto do objeto quanto da relação ao objeto. Saussure cria um problema: afasta o sujeito psicológico - da percepção e da cognição - do cerne de sua reflexão. Esse gesto, embora não seja seguido por uma teorização sobre o sujeito falante, abre o caminho para uma escuta outra para a fala.

Caminho que é assumido por Cláudia Lemos que, sob efeito da Psicanálise, pôde introduzir aí uma reflexão sobre o sujeito compatível com o gesto saussureano de expulsão do sujeito psicológico. O sujeito que comparece em seu trabalho é efeito da linguagem -e é isso que a noção de captura por ela introduzida na reflexão sobre o processo de aquisição da linguagem estenografa. Essa noção produz, efetivamente, uma reviravolta, uma inversão: de centro de captação, em que ele é confundido com faculdades biologicamente determinadas, o sujeito passa a capturado. Trata-se de um processo de subjetivação entendido como de destituição do ser pela linguagem, ou seja, o que a Psicanálise introduz e que produz impacto na reflexão de Cláudia Lemos, é a hipótese de uma impossível coincidência entre organismo e sujeito.

Dessa impossível coincidência pode-se retirar outra: a impossível coincidência ou, melhor, a necessária dissimetria entre ouvir e escutar. Isso significa dizer que não é a criança que se apropria da linguagem via capacidades perceptuais e cognitivas, mas, diferentemente, ela é capturada numa estrutura que implica três pólos: o do sujeito, o da 
língua e o do outro. Vê-se que essa estrutura dá reconhecimento tanto à língua como ao outro - outro não como socius e, sim, "como instância do funcionamento da língua constituída" (De Lemos, 1992 e outros). É a partir daí que o processo de aquisição da linguagem passa a ser pensado, na reflexão de Cláudia Lemos, como mudança na relação criança-língua-fala, ou seja, como mudança de posição da criança numa estrutura que articula esses três pólos.

A reflexão sobre o movimento da criança na estrutura sujeito-língua-fala é, como se vê, ponto nevrálgico para uma discussão acerca da escuta da criança para a fala e para seu deslocamento da posição de sujeito percipiente para sujeito do inconsciente. Deslocamento necessário para o estabelecimento de balizamentos para uma clínica de linguagem que possa abordar a relação da criança à fala enquanto uma relação atravessada pelo funcionamento da língua - atravessamento, esse, que abre lugar para a emergência do sujeito.

Implicar a linguagem no processo de subjetivação significa, portanto, retirar o sujeito do centro, da posição de percipiente - o que obriga a um afastamento da epistemologia sujeito-objeto comprimida no esquema do arco-reflexo, através do qual se tem procurado apreender, no campo da Fonoaudiologia, as relações do ser vivo com o meio. Dito de outro modo, dependeria de um distanciamento da noção de indivíduo biologicamente equipado para apreender, entre outros, os sons da linguagem, bem como de um movimento de implicação da língua e das operações que ela realiza sobre a materialidade sonora. Mais que isso, interessa implicar o falante na fala. De fato, reconhecer a ordem própria da língua e articulá-la à noção de sujeito da Psicanálise, como faz o Interacionismo proposto por Cláudia Lemos, nos leva à recusa da noção de sujeito epistêmico a que se supõe uma percepção e uma cognição que dirigem sua relação com a linguagem.

Nesse sentido, a tarefa de desnaturalização da relação percepção-linguagem, a ser enfrentada por uma clínica de linguagem, é bastante complexa. A complexidade da tarefa referida envolve, como diz Merleau-Ponty (1945/1999, p. 36), "renunciar aos esquemas de explicação mecanicista", uma renúncia que "na fisiologia dos sentidos, põe imediatamente em xeque nossa idéia mais arraigada do ser", à medida em que não se poderá mais pensar a percepção como uma relação entre "puro objeto físico [e] corpo humano" nem "o percebido como o resultado interior dessa ação". Complexidade que remete, portanto, à desconstrução da idéia de percepção vigente na Fonoaudiologia e em muitas áreas da ciência e que exige, além disso, que se assuma o corpo não como domínio de sensações puras. É também Merleu-Ponty quem acrescenta que "não se pode perceber sem corpo mas [...] é preciso reexaminar a definição de corpo" (id., p. 37). Uma tal redefinição de corpo, no campo da Aquisição da Linguagem, é operada pela noção de captura postulada por Cláudia Lemos - de anterioridade lógica da língua sobre o sujeito e, portanto, sobre a percepção da fala.

Trata-se, portanto, de implicar língua e falante na fala. A conseqüência dessa implicação barra a possibilidade de conceber o sujeito como um organismo com capacidades perceptuais indiferentes aos efeitos da língua e exige o estabelecimento de uma reflexão sobre o corpo que, porque capturado pelo funcionamento da linguagem, e aqui utilizo palavras de Cláudia Lemos, "transforma as semelhanças, identidades e diferenças que são alçadas do fundo de sonoridade em saliências que não são perceptuais. Trata-se, enfim, de um funcionamento 
Cadernos de Estudos Lingüísticos 47(1) e (2) - Jan./Dez. 2005

que "faz com que a orelha do indivíduo que ouve passe a ser a orelha daquele que escuta" (De Lemos, 1995b).

Vê-se, assim, que a noção de captura é central ao encaminhamento da discussão sobre o ouvir e o escutar - na clínica de linguagem ela é fundamental para que se possa:

1) Suspender os efeitos imaginários que regem a apreensão do jogo de relações entre as falas que ali ocorrem, e

2) Estabelecer uma abordagem teoricamente sustentada da trama que inclui a relação do paciente e do terapeuta com as próprias falas e com as falas um do outro.

O cumprimento desses passos em direção à circunscrição de uma noção de escuta na clínica de linguagem exige, em primeiro lugar, o reconhecimento de que, nesse campo, a trama de relações entre falas delineia os contornos da singularidade da escuta implicada tanto na fala sintomática do paciente quanto na escuta-interpretação do terapeuta.

Penso que a consideração da implicação da escuta do paciente em sua fala sintomática - implicação que aponta para um modo singular de captura - é passo inicial para a circunscrição de uma noção de interpretação particular à clínica de linguagem. Nesse sentido, um caminho a ser explorado em direção ao imbricamento entre a singularidade da falaescuta do paciente e uma interpretação que incida sobre essa singularidade passa por uma reflexão acerca da possibilidade de fazer render uma noção de captura também no que diz respeito à relação do terapeuta com a fala do paciente. Trata-se de pensar o terapeuta na clínica de linguagem enquanto aquele que se faz terapeuta no momento em que sua escuta é capturada pela singularidade da fala-escuta do paciente. Ao falar em "escuta capturada pela fala-escuta do paciente" pretendo apontar para o fato de que, embora a marca de uma inscrição teórica seja fundamental à escuta do terapeuta, o imediatismo e a imprevisibilidade do instante clínico em que ele é convocado a produzir uma interpretação exige uma implicação de outra natureza ${ }^{3}$. É nesse sentido que o duplo compromisso mencionado no início deste trabalho - que envolve a articulação entre a universalidade de uma instância teórica particular e a singularidade incontornável de uma fala sintomática (Andrade, 1998) - deve ser reafirmado.

Os efeitos da discussão que procurei encaminhar na circunscrição de uma clínica de linguagem é questão a ser explorada de modo mais aprofundado ${ }^{4}$. As considerações aqui apresentadas tiveram por objetivo apontar para questões instigadas, em grande parte, pela reflexão de Cláudia Lemos e para possibilidades de seu deslocamento para campos outros.

\section{REFERÊNCIAS BIBLIOGRÁFICAS}

ANDRADE, L. (1998). The status of linguistic data in language assessment procedures. In: 6th International Pragmatics Conference. Reims, França. A sair em M. F. Lier-De Vitto \& L. Arantes (orgs.) Aquisição, Patologias e Clínica de Linguagem.

${ }^{3}$ A questão dos efeitos da fala do paciente sobre a escuta do terapeuta é tratada de modo original e instigante por Lier-De Vitto e Arantes (1998).

${ }^{4}$ Um passo nessa direção é dado em Andrade (2003), em "Ouvir e escutar na constituição da clínica de linguagem", tese de doutoramento (inédita, LAEL/PUCSP). 
ANDRADE, L. (2000). Audição e Linguagem: a natureza é a mesma? In: R. M.Freire (org.) Fonoaudiologia: Seminários de Debates, Interfaces, v. 3, São Paulo: Roca.

ARAÚJO, S.M.M. (2002). O Fonoaudiólogo frente à fala sintomática de crianças: uma posição terapêutica? Tese de doutorado. USP.

LACAN, J. (1954/87). O Seminário - Livro 2 - O eu na teoria de Freud e na técnica da Psicanálise. Rio de Janeiro: Jorge Zahar Editor.

LEMOS, C.T.G. (1995a). Língua e discurso na teorização sobre aquisição de linguagem. Letras de Hoje, v.30, $\mathrm{n}^{\circ} 4$.

(1992). Los procesos metafóricos y metonímicos como mecanismos de cambio. Substratum I-1. . (1995b). Corpo e Linguagem. In: L.C. Junqueira Filho (org) Corpo Mente: uma fronteira móvel. São Paulo: Casa do Psicólogo. (1998). 'Sobre a aquisição da escrita: algumas questões'. In R. Rojo (org) Alfabetização e Letramento. Campinas: Mercado de Letras. . (2002). Das vicissitudes da fala da criança e de sua investigação. E. Orlandi (org.) História das idéias lingüísticas. Campinas: Pontes (no prelo)

Lier-De VitTo, M.F. \& ARANTES, L. (1998). Sobre os efeitos da fala da criança: da heterogeneidade desses efeitos. Letras de Hoje, v.33, n.2 (65-72). Porto Alegre: EDIPUCRS.

MERLEAU-PONTY, M. (1945/1999). Fenomenologia da Percepção. São Paulo: Martins Fontes.

SAUSSURE, F. (1916/1971). Curso de lingüística Geral. São Paulo: Cultrix. 